\title{
ESPECTROFOTOMETRIA DE PROTEÍNAS TOTAIS EM PLASMA DE SANGUE BOVINO POR ANÁLISE EM FLUXO
}

\author{
Gilmara Caseri de Luca ${ }^{1,3}$; Boaventura Freire dos Reis²* \\ ${ }^{1}$ Pós-Graduanda do Instituto de Química de São Carlos/USP - CEP: 13560-970 - São Carlos, SP. \\ ${ }^{2}$ Lab. de Química Analítica - USP/CENA, C.P. 96 - CEP: 13400-970 - Piracicaba, SP. \\ ${ }^{3}$ Bolsista FAPESP. \\ *Autor correspondente <reis@cena.usp.br>
}

\begin{abstract}
RESUMO: A concentração de proteína total em plasma é um parâmetro utilizado no controle da saúde e nutrição animal, sendo que a faixa de concentração considerada normal para animais em bom desenvolvimento situa-se entre 60 e $85 \mathrm{~g} \mathrm{~L}^{-1}$. Os métodos analíticos propostos para esta determinação geralmente apresentam como limitação a excessiva manipulação das amostras. Este trabalho descreve o desenvolvimento de um procedimento de análises em fluxo para a determinação de proteína total em plasma de sangue bovino, empregando o método do Biureto. O sistema em fluxo, constituído por um injetor comutador automático e uma válvula solenóide de três vias controlados por um microcomputador, foi projetado visando permitir diluição em linha das amostras. Um fator de diluição era estimado procedendo-se a diluição em linha de uma solução com concentração conhecida de albumina e este fator era empregado para o cálculo final das concentrações das amostras após diluição em linha. As soluções das amostras eram inseridas através da válvula solenóide, a qual permitia precisas diluições, diminuindo operações manuais. A faixa analítica estabelecida foi entre 2,5 e $20,0 \mathrm{~g} \mathrm{~L}^{-1}$, e considerando a diluição gerada, amostras de plasma bovino contendo entre 12,5 e 100,0 $\mathrm{g} \mathrm{L}^{-1} \mathrm{de}$ proteína total puderam ser analisadas. O procedimento apresentou desvio padrão relativo de $2,8 \%$, e a freqüência analítica alcançada foi de 76 determinações por hora. Os resultados foram comparados com o método tradicional de análises (Biureto) e não foram observadas diferenças estatisticamente significativas a 95\%.
\end{abstract}

Palavras-chave: determinação de proteína, diluição em linha, sistema de análise em fluxo, plasma animal

\section{SPECTROPHOTOMETRY OF TOTAL PROTEIN IN BOVINE BLOOD PLASMA BY FLOW ANALYSIS}

\begin{abstract}
Total protein concentration in plasma samples is normally used as a parameter to control animal health and nutritional conditions. Normal concentration levels are in the range of 60 to $85 \mathrm{~g} \mathrm{~L}^{-1}$ total protein for animals of good development. The methods proposed for its determination generally present as a disadvantage an excessive handling during operation. In this work an automated flow procedure for total protein determination in bovine serum samples, employing the Biuret method, was developed. The system, including an automatic injector commutator and a three way solenoid valve computer controlled, was designed in order to permit on line sample dilution. Since protein standard solutions were introduced with and without dilution. A dilution factor was estimated and used to calculate protein concentration obtained after on-line dilution of the samples. Solutions samples were inserted through a three way solenoid valve that allows precise dilution minimizing hand operations. The analytical range for total protein determination was 2.5 to $20.0 \mathrm{~g} \mathrm{~L}^{-1}$, and considering the dilution employed, bovine plasma samples with 12.5 to $100.0 \mathrm{~g} \mathrm{~L}^{-1}$ of total protein were analysed. The procedure presented a $2.8 \%$ rsd and analytical frequency of 76 determinations per hour. Results were in good agreement with the traditional method (Biuret) and no significant difference was verified at $95 \%$.

Key words: protein, on line dilution, flow system, blood plasma
\end{abstract}

\section{INTRODUÇÃO}

A determinação de proteínas totais em plasma de sangue bovino é utilizada como um parâmetro no controle da saúde e nutrição animal (FAO, 1993). Os valores de referência em soro sangüíneo de bovinos situam-se entre 60 a $85 \mathrm{~g} \mathrm{~L}^{-1}$, sendo que níveis mais baixos são verificados em casos de deficiência de proteína na dieta; insuficiência hepática; aproveitamento inadequado da proteína ingerida; hemorragias; e perda da proteína intestinal ou renal. Quando a concentração de proteína total no plasma sangüíneo aumenta, podem ser observados casos de desidratação bem como doenças crônicas ou intermediárias (FAO, 1993; Lindsey, 1996).

Ao longo de décadas, inúmeros pesquisadores têm se dedicado ao desenvolvimento de metodologias e procedimentos visando a determinação de proteína total em diversos tipos de amostras como por exemplo sangue, urina e leite. O método de Kjedahl (AOAC, 1995), é um método clássico de análises no qual se determina a concentração de nitrogênio total após decomposição da amostra com ácido sulfúrico. É empregado como método de referência, mas apresenta 
como limitação o tempo longo exigido por análise e possíveis erros nos resultados ocasionados pela presença de nitrogênio não protéico na amostra. Outros procedimentos instrumentais de análises têm sido também empregados utilizando cromatografia (Hayakawa et al., 1997), fluorimetria (Yokoyama et al., 1990), polarografia (Perez \& Frutos, 1995) e espectrofotometria (Bradford, 1976; Goren \& Li, 1986; Guo \& Shen, 1999) como técnicas de detecção e quantificação, visando suprir aplicações nas áreas clinica e nutricional, entre outras. Os métodos espectrofotométricos são os mais utilizados, e revisões recentes desses métodos apontaram as vantagens e desvantagens das principais reações empregadas (Zaia et al., 1998; Sapan et al., 1999). Parâmetros importantes a serem considerados para a escolha da metodologia são a concentração da espécie de interesse, que pode variar muito dependendo da natureza da amostra (plasma ou soro de sangue, urina, fluido espinal, leite, etc.), e possíveis interferências. No caso específico de soro ou plasma sangüíneo, o método do Biureto, cujo procedimento é manual (FAO, 1993), tem sido o mais indicado para a determinação de proteínas totais (Zaia et al., 1998). Um dos fatores negativos para a utilização de procedimentos manuais é a manipulação excessiva das amostras, aumentando o risco de contaminações. Além disso, as etapas analíticas envolvidas nestes procedimentos são lentas, trabalhosas e dispendiosas, potencializando a necessidade de se recorrer a procedimentos automatizados para diminuir o consumo de reagentes e o tempo para obtenção dos resultados.

Para facilitar a operação, minimizar contaminações, manipulação das amostras e aumentar a freqüência analítica, sistemas de análise em fluxo FIA (Ruzicka \& Hansen, 1988) podem ser empregados. Os sistemas FIA são ótimos gerenciadores de soluções, apresentam facilidade operacional, podendo ser adaptados ao desenvolvimento analítico. Em tais sistemas, reações rápidas ou lentas podem ser implementadas como adição de reagentes, diluição ou pré-concentração das amostras, separação de espécies potencialmente interferentes, entre outros procedimentos, que normalmente são realizados manualmente. Com a proposta de sistemas empregando multicomutação (Reis et al., 1994) os sistemas de análise em fluxo tornaram-se muito mais versáteis e robustos.

Explorando tais potencialidades, neste trabalho foi desenvolvido um procedimento em fluxo automatizado para a determinação de proteínas totais em plasma de sangue bovino empregando a reação do Biureto (Lindsey, 1996). O sistema proposto é composto por um injetor comutador e uma válvula solenóide de três vias cujo funcionamento é controlado por um microcomputador.

\section{MATERIAL E MÉTODOS}

Todos os reagentes utilizados foram de grau analítico e as soluções foram preparadas com água destilada e deionizada.

Soluções padrão de proteína contendo 0,$0 ; 2,5$; 5,$0 ; 10,0 ; 15,0$ e $20,0 \mathrm{~g} \mathrm{~L}^{-1}$ foram preparadas dissolvendo-se 0,$00 ; 0,125 ; 250,0 ; 500,0 ; 750,0$ e 1.000 $\mathrm{mg}$ de albumina de soro bovino (fração $\mathrm{V}$, Merck) em $50,0 \mathrm{~mL}$ de cloreto de sódio $0,14 \mathrm{~mol} \mathrm{~L}^{-1}$. Estas soluções eram preparadas a cada três dias, e armazenadas em frascos de vidro. Quando não em uso, eram mantidas sob refrigeração.

Reagente Biureto contendo $6,0 \mathrm{~g} \mathrm{~L}^{-1}$ de sulfato de cobre ( $\mathrm{CuSO}_{4} .5 \mathrm{H}_{2} \mathrm{O}$; Merck), $5,0 \mathrm{~g} \mathrm{~L}^{-1}$ de iodeto de potássio (KI; Merck), 18,0 $\mathrm{g} \mathrm{L}^{-1}$ tartarato de sódio e potássio $\mathrm{KNaC}_{4} \mathrm{H}_{4} \mathrm{O}_{6} \cdot 4 \mathrm{H}_{2} \mathrm{O}$ ) Merck), em 0,2 $\mathrm{mol} \mathrm{L}^{-1}$ de hidróxido de sódio $(\mathrm{NaOH})$. Esta solução era preparada semanalmente, armazenada em frasco de polietileno e protegida da luz.

Amostras de plasma bovino, foram cedidas pelo Laboratório de Ciências Animais do Centro de Energia Nuclear na Agricultura (CENA/USP). As amostras de sangue animal foram coletadas diretamente dos animais por punção venosa na cauda ou veia jugular empregando agulha de calibre 18 para evitar hemólise. As amostras foram recolhidas em tubos de ensaio do tipo Vacutainer ${ }^{\circledast}$, os quais são comercializados esterilizados, à vácuo e com anticoagulante (heparina sódica). Após coleta, o tubo foi invertido cuidadosamente para que ocorresse a mistura e centrifugados durante $12 \mathrm{~min}$ a $2500 \mathrm{rpm}$. Uma vez separado o plasma das células, o mesmo foi removido com o auxílio de pipetador automático e transferido para frascos de polietileno esterilizados, para posterior análise. Esse procedimento de coleta e preparo da amostra é recomendado por Nogueira et al. (1998).

O sistema em fluxo era constituído por uma bomba peristáltica Ismatec IPC-8, com tubos de Tygon de diferentes diâmetros internos; um espectrofotômetro Femto, modelo 482, equipado com cubeta de fluxo (100 $\mu \mathrm{L}, 10 \mathrm{~mm}$ passo óptico); um registrador potenciométrico ECB, modelo RB201; um injetor comutador automático; uma válvula solenóide de três vias (161T031) controlada por um microcomputador equipado com uma interface de controle PCL 711s da American Advantech. As bobinas de mistura e reação foram confeccionadas com tubos de polietileno de $0,8 \mathrm{~mm}$ de diâmetro interno.

O sistema em fluxo utilizado para a determinação de proteína total em plasma de sangue bovino é mostrado na Figura 1. O sistema de inserção das soluções é constituído por duas partes: uma válvula solenóide de três vias $\left(\mathrm{V}_{1}\right)$ e um injetor comutador. Ambos podem funcionar independentemente ou simultaneamente. Na posição representada na Figura. 1, a válvula está desligada e um fluxo de água é aspirado através da bobina de mistura $B_{1}$ e da alça de amostragem $\mathrm{L}$ em direção ao descarte. A solução 
transportadora é bombeada através do percurso analítico e o reagente $R_{1}$ é reciclado. Acionando-se a válvula $V_{1}$, a solução da amostra é aspirada através de $B_{1}$, preenche $\mathrm{L}$ e seu excesso é descartado. Após um período de tempo selecionado para preencher $\mathrm{L}$, o injetor é comutado para a posição alternativa, a alça de amostragem é inserida no percurso analítico, e a válvula $\mathrm{V}_{1}$ é desligada. $\mathrm{O}$ reagente $\mathrm{R}_{1}$ é adicionado à zona da amostra através do ponto de confluência $x$, e a mistura amostra e reagente flui através da bobina de reação $B_{2}$ em direção ao detector. Após a obtenção do máximo do sinal analítico, a parte central do injetor volta à posição de origem e um novo ciclo se inicia acionando-se a válvula $\mathrm{V}_{1}$ para preenchimento de $\mathrm{L}$ com a solução da amostra.

O programa para controle de acionamento da válvula solenóide e do injetor comutador automático foi escrito em linguagem QuickBASIC 4.5. O fluxograma do programa é mostrado na Figura 2.

Os estudos para definir o volume de amostra, forma de introdução do reagente e tempo de reação foram conduzidos empregando o sistema sem a válvula solenóide, e desta forma, a solução da amostra era introduzida diretamente através da alça de amostragem (L). Após estas otimizações, a válvula solenóide foi adaptada ao injetor comutador (Figura 1), visando promover diluição em linha das amostras. Estudaram-se, então, possíveis diluições em linha das amostras, introduzindo-se no sistema uma solução de trabalho com concentração conhecida de albumina. Para estimar os fatores de diluição, variou-se o tempo da válvula solenóide nas condições ligada-desligada, e o número de repetições desta seqüência.

Definidas as condições de trabalho, a exatidão do procedimento foi avaliada comparando-se o procedimento proposto com o método oficial para a determinação de proteína total em fluídos biológicos.

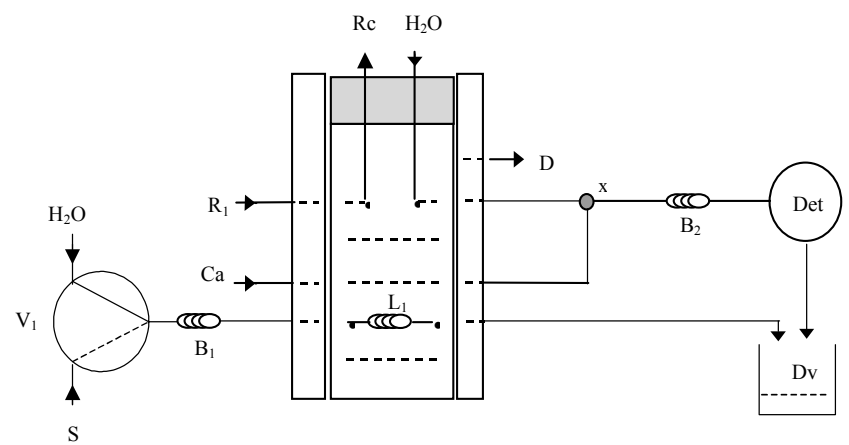

Figura 1 - Diagrama do sistema em fluxo empregado para a determinação de proteína total em plasma sangüíneo. $\mathrm{V}_{1}$ = válvula solenóide de três vias; $\mathrm{B}_{1}=$ bobina de mistura; $\mathrm{B}_{2}=$ bobina de reação; $\mathrm{Ca}=\mathrm{H}_{2} \mathrm{O}(4,0 \mathrm{~mL}$ $\left.\mathrm{min}^{-1}\right) ; \mathrm{R}_{1}=$ reagente biureto $\left(4,0 \mathrm{~mL} \mathrm{~min}^{-1}\right) ; \mathrm{L}_{1}=$ alça de amostragem; $S=$ amostra $\left(2,0 \mathrm{~mL} \mathrm{m^{-1 }}\right)$; Det $=$ espectrofotômetro $(\lambda=546 \mathrm{~nm})$; $\mathrm{Dv}=$ vaso de descontaminação; $x=$ ponto de confluência; $D=$ descarte.

\section{RESULTADOS E DISCUSSÃO}

Os estudos para automatização do método direcionado à determinação de proteínas totais em plasma de sangue bovino foram conduzidos buscando estabelecer uma faixa analítica de concentração adequada a esta determinação. Embora os níveis de referência indiquem concentrações na faixa entre 60,0 e $85,0 \mathrm{~g} \mathrm{~L}^{-1}$, a faixa analítica estabelecida inicialmente foi entre 2,5 e $20,0 \mathrm{~g} \mathrm{~L}^{-1}$ de albumina, pressupondo diluições das amostras. Esta estratégia foi adotada considerando que o reagente empregado no preparo das soluções padrão tem um alto custo e as soluções são pouco estáveis e apresentam certa dificuldade no preparo.

Durante o dimensionamento do sistema e definição dos principais parâmetros envolvidos na determinação de proteína total, a válvula solenóide foi excluída do sistema (Figura 1) e os estudos foram conduzidos apenas empregando-se o injetor comutador.

Em sistemas FIA, o volume da solução de amostra é definido pela dimensão da alça de amostragem. Desta forma, fixou-se o comprimento da bobina de reação $\left(B_{2}\right)$ em $300 \mathrm{~cm}$ e variou-se o comprimento de $\mathrm{L}$ em 20,50 e $100 \mathrm{~cm}(0,8 \mathrm{~mm}$ d.i. $)$,

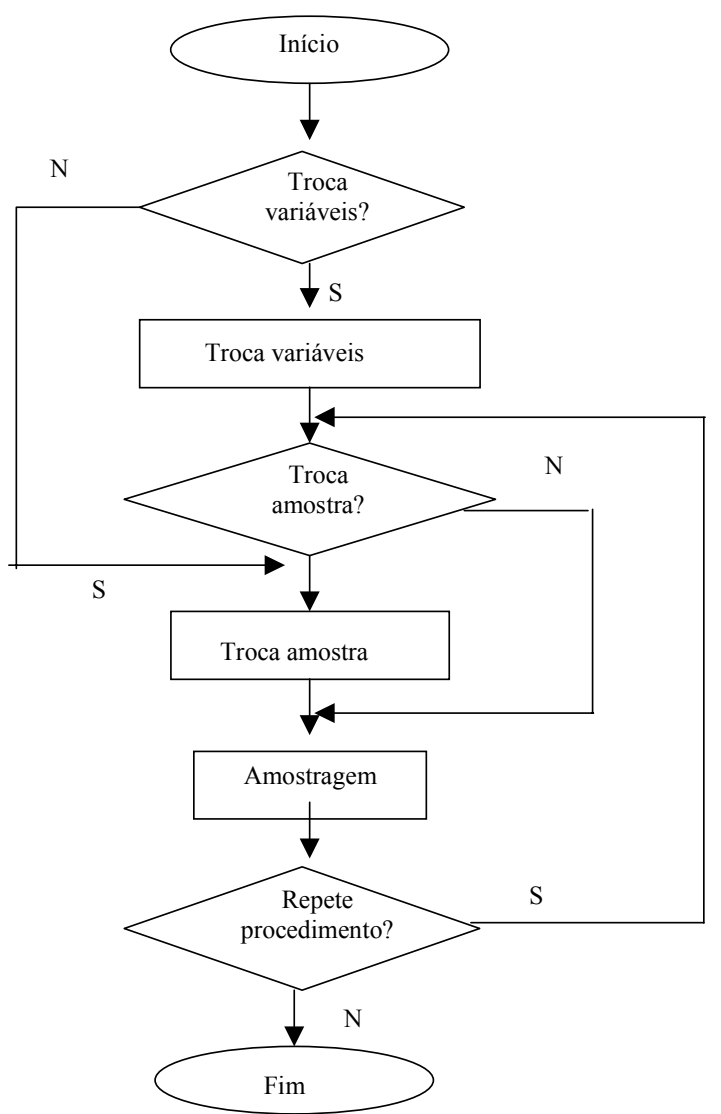

Figura 2 - Fluxograma do programa de controle. O fluxograma refere-se ao funcionamento do sistema mostrado na Figura 1, empregado na determinação de proteínas totais. 
correspondendo a volumes de 100,250 e $500 \mu \mathrm{L}$ e, em função da resposta do sinal analítico obtido, fixou-se o volume da solução da amostra em $100 \mu \mathrm{L}(20 \mathrm{~cm})$. Variou-se, então a dimensão da bobina de reação $B_{2}$, correspondente ao tempo disponível para 0 desenvolvimento da reação, em 100, 200 e $300 \mathrm{~cm}$. Foi observado um aumento de $30 \%$ nos sinais quando variou-se a dimensão de $\mathrm{B}_{2}$ de 100 para $200 \mathrm{~cm}$. Acima de $200 \mathrm{~cm}$, apesar do tempo de reação ser maior, observou-se uma diminuição de $5 \%$ do sinal monitorado. Esta diminuição pode ser atribuída à dispersão do produto formado na solução transportadora durante seu transporte até o detector. A bobina de reação foi fixada em $200 \mathrm{~cm}(0,8 \mathrm{~mm}$ d.i. $)$.

A relação entre as vazões da solução transportadora e da solução do reagente $R_{1}$, era inicialmente 1:1 (2,4 mL $\mathrm{min}^{-1}$ cada uma). Com estas vazões, quando a zona da amostra atingia o ponto de confluência $x$, sua concentração, bem como a do reagente $R_{1}$, eram reduzidas à metade. Visando promover uma menor diluição da zona da amostra no percurso analítico, a vazão do reagente foi alterada de $2,4 \mathrm{~mL} \mathrm{~min}^{-1}$ para $1,2 \mathrm{~mL} \mathrm{~min}^{-1}$. Esta redução na vazão da solução do reagente $R_{1}$ diminuiu a diluição da zona da amostra, mas aumentou a diluição do reagente, acarretando perda em linearidade. Fixou-se a vazão do reagente em 1,2 $\mathrm{mL} \min ^{-1}$ e variou-se a concentração do reagente em 3,0; 4,5 e 6,0 $\mathrm{g} \mathrm{L}^{-1}$ de sulfato de cobre. A concentração de tartarato de sódio e potássio, empregado para estabilizar os íons cobre em solução, também foi aumentada proporcionalmente. A solução contendo $6,0 \mathrm{~g} \mathrm{~L}^{-1} \mathrm{CuSO}_{4} \cdot 5 \mathrm{H}_{2} \mathrm{O}, 18,0 \mathrm{~g} \mathrm{~L}^{-1}$ $\mathrm{KNaC}_{4} \mathrm{H}_{4} \mathrm{O}_{6} \cdot 4 \mathrm{H}_{2} \mathrm{O}$, e $5,0 \mathrm{~g} \mathrm{~L}^{-1} \mathrm{KI}$ em $0,2 \mathrm{~mol} \mathrm{~L}^{-1} \mathrm{NaOH}$, foi a que apresentou melhores resultados em termos de linearidade $(r=0,998)$ e sensibilidade (Figura 3$)$, sendo fixada para a continuidade do procedimento.

Uma vez definidas as condições para o desenvolvimento da reação, alterou-se a forma de inserção do reagente: de bombeamento contínuo para inserção intermitente. O sistema empregando fluxos intermitentes foi proposto por Zagatto et al. (1980), que demonstraram a funcionalidade desta proposta na determinação de nitrato em águas. Esta estratégia foi empregada visando diminuir o consumo de reagente, que era desperdiçado durante a etapa de limpeza. $\mathrm{Na}$ posição do injetor na qual $R_{1}$ era reciclado, um fluxo de água com maior vazão era introduzido através do ponto de confluência $x$ (Figura 1), o que favorecia também uma limpeza mais rápida do sistema.

Conforme mencionado anteriormente, o desenvolvimento deste procedimento para a determinação de proteína total em plasma sangüíneo previa diluição das amostras, para que a concentração das mesmas estivesse dentro da faixa de resposta linear do método. Incluiu-se então no sistema, uma válvula solenóide de três vias, a qual tinha a função de permitir a diluição em linha das amostras (Figura 1). A inclusão

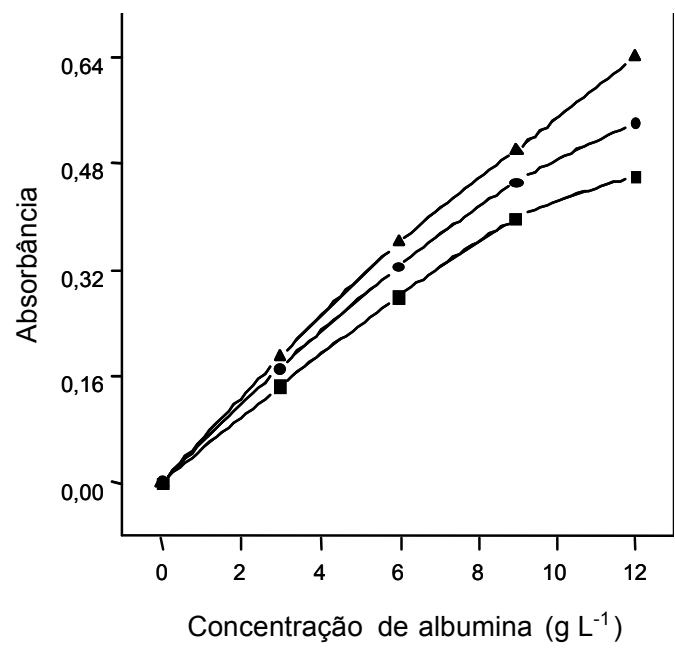

Figura 3 - Efeito da concentração do reagente. -n- : $3,0 \mathrm{~g} \mathrm{~L}^{-1}$ $\mathrm{CuSO}_{4} \cdot 5 \mathrm{H}_{2} \mathrm{O} ;-\mathrm{l-}: 4,5 \mathrm{~g} \mathrm{~L}^{-1} \mathrm{CuSO}_{4} \cdot 5 \mathrm{H}_{2} \mathrm{O} ;-\mathrm{s}-: 6,0 \mathrm{~g} \mathrm{~L}^{-1}$ $\mathrm{CuSO}_{4} \cdot 5 \mathrm{H}_{2} \mathrm{O}$. Resultados obtidos empregando-se o sistema da Figura 1.

desta válvula permitia que as soluções de referência fossem inseridas sem diluição, acionando-se a válvula $\mathrm{V}_{1}$ por um período de tempo suficientemente longo para que a alça de amostragem $L$ fosse preenchida. No caso das amostras cuja concentração do analito era maior, diluições podiam ser realizadas variando-se o tempo de acionamento de $\mathrm{V}_{1}$, intercalando um volume da solução da amostra com o do diluente. Empregando-se esta configuração (Figura 1), o volume da solução da amostra inserido no percurso analítico era sempre o mesmo, sendo portanto o fator dispersão inalterado. Desta forma, estudou-se possíveis diluições da amostra, variando-se os intervalos de tempo de $V_{1}$ nas posições liga-desliga, para inserção das soluções da amostra e do diluente. Quando a $V_{1}$ era acionada, uma alíquota da solução da amostra era inserida em $B_{1}$, e quando $V_{1}$ era desligada, inseria-se uma alíquota do diluente. $O$ número de ciclos selecionado para repetir esta seqüência, era estabelecido em função do tempo necessário para completo preenchimento de $\mathrm{L}$ com a solução a ser analisada.

$\mathrm{O}$ intervalo de tempo de $\mathrm{V}_{1}$ acionada foi variado em 0,$2 ; 0,3 ; 0,4 ; 0,5 ; 0,6 ; 0,7$ e 0,8 s e observou-se que quando períodos menores que $0,5 \mathrm{~s}$ eram empregados, o desvio padrão relativo estimado era mais expressivo $(\sim 7 \%)$. Fixou-se o tempo de inserção da alíquota da amostra em $0,5 \mathrm{~s}$ e variou-se o tempo de inserção da solução diluente em 0,$5 ; 1,0 ; 1,5 ; 2,0 ; 2,5 ; 3,0$ s. Podese observar através da Tabela 1 uma boa correlação entre os fatores obtidos e os valores teóricos quando o tempo de inserção do diluente foi fixado em $2,0 \mathrm{~s}$, sendo o fator de diluição estabelecido de 5 vezes. $O$ fator diluição $(F)$, era estimado inserindo-se a solução de referência de maior concentração $\left(20,0 \mathrm{~g} \mathrm{~L}^{-1}\right) \operatorname{com}\left(C_{\mathrm{d}}\right)$ e sem $\left(C_{i}\right)$ o procedimento de diluição. As concentrações eram calculadas através da curva analítica, e a razão entre $C_{i}$ e $C_{d}$ gerava o fator de diluição real $\left(F=C_{i} / C_{d}\right)$. Este fator era utilizado para cálculo das concentrações 
Tabela 1 - Fatores de diluição obtidos empregando-se uma solução contendo $20,0 \mathrm{~g} \mathrm{~L}^{-1}$ de albumina.

\begin{tabular}{lccc}
\hline $\begin{array}{l}\mathrm{V}_{1} \text { Liga - } \\
\text { desliga }(\mathrm{s})^{*}\end{array}$ & $\begin{array}{c}\text { Fator de } \\
\text { diluição teórico }\end{array}$ & $\begin{array}{c}\text { Fator de diluição } \\
\text { encontrado }\end{array}$ & $\begin{array}{c}\text { Erro } \\
(\%)\end{array}$ \\
\hline $0,5-0,5$ & 2 & 2,3 & 15 \\
$0,5-1,0$ & 3 & 3,1 & 3 \\
$0,5-1,5$ & 4 & 4,2 & 5 \\
$0,5-2,0$ & 5 & 5,3 & 6 \\
$0,5-2,5$ & 6 & 7,4 & 23 \\
$0,5-3,0$ & 7 & 9,4 & 34 \\
$0,5-4,5$ & 10 & 17,3 & 73 \\
\hline
\end{tabular}

*referem-se aos intervalos de tempo para inserção da solução da amostra e da solução do diluente.

Tabela 2 - Comparação de resultados obtidos na determinação de proteína total.

\begin{tabular}{ccc}
\hline Amostra* $^{*}$ & Sistema Proposto & $\begin{array}{c}\text { Método Tradicional } \\
\text { (Biureto) }\end{array}$ \\
\hline 1 & $92 \pm 3$ & $88 \pm 2$ \\
2 & $85 \pm 2$ & $89 \pm 3$ \\
3 & $81 \pm 2$ & $82 \pm 2$ \\
4 & $72 \pm 2$ & $76 \pm 1$ \\
5 & $81 \pm 2$ & $77 \pm 1$ \\
6 & $91 \pm 3$ & $89 \pm 2$ \\
7 & $89 \pm 3$ & $90 \pm 3$ \\
8 & $86 \pm 2$ & $83 \pm 1$ \\
9 & $86 \pm 2$ & $86 \pm 1$ \\
10 & $76 \pm 2$ & $82 \pm 3$ \\
11 & $77 \pm 2$ & $87 \pm 2$ \\
12 & $78 \pm 3$ & $83 \pm 3$ \\
13 & $70 \pm 2$ & $84 \pm 2$ \\
14 & $85 \pm 2$ & $88 \pm 2$ \\
15 & $86 \pm 2$ & $87 \pm 2$ \\
\hline
\end{tabular}

*De 1 a 8 os resultados correspondem a amostras de plasma de sangue eqüino e de 9 a 15 a amostras de plasma de sangue bovino. Os resultados são médias de 3 determinações.

finais das amostras, multiplicando-se as concentrações encontradas pelo fator estabelecido.

Para verificar se a mistura amostra-diluente era eficiente, variou-se o dimensionamento de $B_{1}$ em 10, 20 e $40 \mathrm{~cm}$, aumentando-se proporcionalmente o número de ciclos da seqüência de acionamento de $V_{1}$ para completo preenchimento de L. Não foi observada melhoria em repetibilidade com o aumento na dimensão de $B_{1}$, sendo esta fixada em $10 \mathrm{~cm}(0,8 \mathrm{~mm}$ d.i.).

Um conjunto de amostras de plasma de sangue bovino foi analisado e os resultados foram comparados com aqueles obtidos empregando o método tradicional de análises (Tabela 2). A análise estatística dos resultados (teste $t$-pareado) demonstrou que não há diferença estatisticamente significativa em nível de $95 \%$ de confiança entre os procedimentos utilizados. O desvio padrão relativo de $2,8 \%(n=10)$ foi estimado para uma amostra típica de plasma de sangue bovino $\left(76 \mathrm{~g} \mathrm{~L}^{-1} \mathrm{de}\right.$ proteína).

O sistema apresentou ótima estabilidade durante o período de trabalho de 4 horas, e uma freqüência analítica de 76 determinações por hora. No sistema

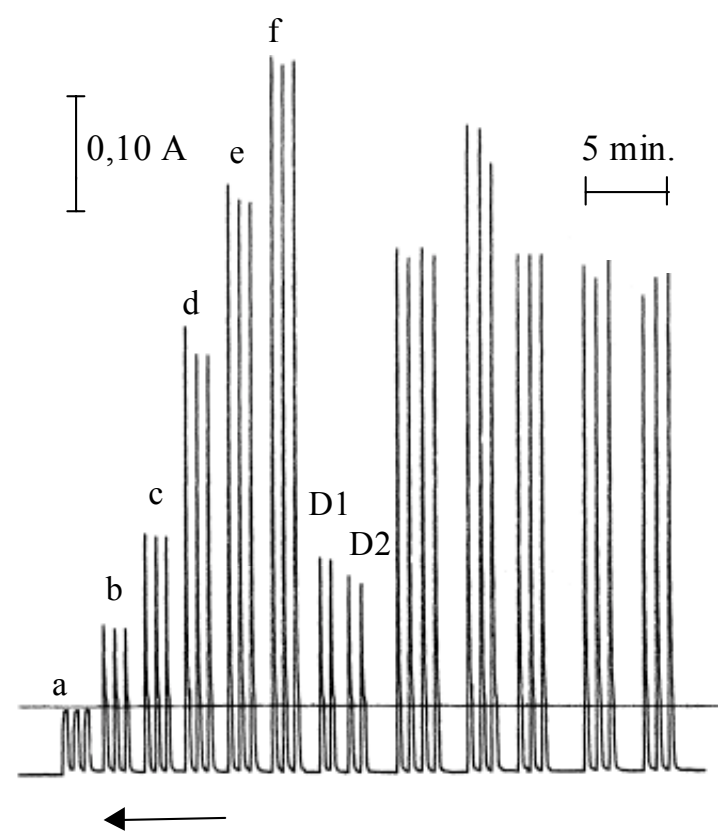

Figura 4 - Registro de rotina para a determinação de proteína totalem plasma de sangue animal. Da esquerda para a direita os sinais identificados pelas letras $a$; b; c; d; e e f correspondem respectivamente às soluções contendo 0,$0 ; 2,5 ; 5,0 ; 10,0 ; 15,0$ e $20,0 \mathrm{~g} \mathrm{~L}^{-1}$ de albumina. D1 e D2 solução contendo $20,0 \mathrm{~g} \mathrm{~L}^{-1}$ após diluição de 4 e 5 vezes. Demais sinais: amostras de plasma animal. A seta indica o sentido do papel.

proposto, a aquisição de dados foi realizada através de um registrador potenciométrico e parte de um registro de rotina é apresentado na Figura 4. Esse sistema de aquisição de dados poderia ser substituído pela aquisição de dados via computador, reduzindo o risco de erros na transcrição de resultados e facilitando a operacionalização do método.

Com o sistema proposto, $84 \mu \mathrm{L}$ de amostra e 67 $\mu \mathrm{L}$ do reagente $\left(0,4 \mu \mathrm{g} \mathrm{CuSO}_{4} .5 \mathrm{H}_{2} \mathrm{O} ; 1,4 \mu \mathrm{g}\right.$ $\mathrm{KNaC}_{4} \mathrm{H}_{4} \mathrm{O}_{6} \cdot 4 \mathrm{H}_{2} \mathrm{O}$ ); e $0,33 \mu \mathrm{g} \mathrm{KI}$ ) foram gastos por determinação, para amostras com concentrações entre 25 e $100 \mathrm{~g} \mathrm{~L}^{-1}$ de proteína total.

\section{CONCLUSÃO}

O procedimento desenvolvido apresentou maior rapidez na emissão de resultados, menor consumo de reagentes e menor manipulação de amostras quando comparado ao método oficial de análises. A montagem do módulo de análises requer poucos conhecimentos de informática e eletrônica, conhecimentos estes que não representam limitações para sua viabilização. Uma vez montado, o sistema é facilmente operado, sendo recomendado para análises de rotina.

\section{AGRADECIMENTOS}

À FAPESP, ao CNPq, à CAPES e PRONEX pelo suporte financeiro, e ao Laboratório de Ciências e Nutrição Animal do USP/CENA pelas amostras cedidas. 


\section{REFERÊNCIAS BIBLIOGRÁFICAS}

ASSOCIATION OF OFFICIAL AGRICULTURAL CHEMISTS. Official methods of analysis. 16 ed. International, Gaithersburg: AOAC, 1995. Method 991, 20.

BRADFORD, M.M. A rapid and sensitive method for the quantitatin of microgram quantities of protein utilizing the principle of protein-dye binding. Analytical Biochemistry, v.72, p.248-254, 1976.

GOREN, M.P.; LI, J.T.L. The coomassie brilliant blue method understimates drug-induced tubular proteinuria. Clinical Chemistry, v.32, p.386-388, 1986.

GUO, Z.; SHEN, H. A novel method for determination of protein utilizing 4azochromotropic acid phenylfluorone-molybdenum(VI) complex. Analytica Chimica Acta, v.396, p.83-90, 1999.

HAYAKAWA, K.; MASUKO, M.; MINETA, M.; YOSHIKAWA, K.; YANAUCHI, K.; HIRANO, M.; KATSUMATA, N.; TANAKA, T. Serum protein determination by high-performance gel-permeation chromatography. Journal of Chromatography. Part B, v.696, p.19-23, 1997.

FOOD AND AGRICULTURE ORGANIZATION. Animal production and health: nutritional metabolite kit protocols. Seibersdorf: FAO/IAEA, 1993.

LINDSEY, B.J. Amino acids and proteins. In: BISHOP, M.L.; DUBENENGELKIRK, J.L.; FODY, E.P. Clinical chemistry: principles, procedures and correlations. Philadelphia: Lippincott, 1996. p.167-206.

NOGUEIRA, A.R.A.; MACHADO, P.L.O.A.; SANTANA DO CARMO, C.A.F.; FERREIRA, J.R. Manual de Laboratórios: solo, água, nutrição vegetal, nutrição animal e alimentos. 1. Coleta, Acondicionamento e preparo de amostras. São Carlos: EMBRAPA, 1998. 72p.
PEREZ, A.S.; FRUTOS, J.E.F. Study of catalytic polarographic reduction of $\mathrm{Ni}(\mathrm{II})$ in the presence of albumin, immunoglobulins and serum proteins. Determination of total proteins in serum. Analytica Chimica Acta, v.317, p.319-325, 1995.

REIS, B.F.; GINÉ, M.F.; ZAGATTO, E.A.G.; LIMA, J.L.F.C.; LAPA, R.A Multicommutation in flow analysis: 1. Binary sampling - concepts, instrumentation and spectrophotometric determination of iron in plant digests. Analytica Chimica Acta, v.23, p.129-138, 1994.

RUZICKA, J.; HANSEN, E.H. Flow injection analysis. 2.ed. New York: John Wiley \& Sons, 1988. 197p.

SAPAN, V.V.; LUNDBLAD, R.L.; PRICE, N.C. Colorimetric protein assay techniques. Biotechnology and Applied Biochemistry, v.29, p.99-108, 1999

YOKOYAMA, T.; NAKAMURA, N.; KINOSHITA, T. Flow injection fluorimetry of protein using hypochorite-thiamine reagent. Analytical Biochemistry, v.184, p.184-188, 1990.

ZAGATTO, E.A.G.; JACINTHO, A.O; MORTATTI, J.; BERGAMIN FILHO, H. An improved flow injection determination of nitrite in waters by using intermittent flows. Analytica Chimica Acta, v.120, p.399-403, 1980.

ZAIA, D.A.M.; ZAIA, C.T.B.V.; LICHTING, J. Determinação de proteínas totais via espectrofotometria: vantagens e desvantagens dos métodos existentes. Química Nova, v.21, p.787-793, 1998

Recebido em 17.01.01 